Sādhanā Vol. 39, Part 1, February 2014, pp. 123-138. (C) Indian Academy of Sciences

\title{
Development of semi-active hydraulic damper as active interaction control device to withstand external excitation
}

\author{
MING-HSIANG SHIH ${ }^{1}$ and WEN-PEI SUNG ${ }^{2, *}$ \\ ${ }^{1}$ Department of Civil Engineering, National Chi Nan University, Puli, \\ Nantou 545, Taiwan \\ ${ }^{2}$ Department of Landscape Architecture, National Chin-Yi University of Technology, \\ Taichung 41111, Taiwan \\ e-mail: drwpsung@yahoo.com.tw;wps@ncut.edu.tw
}

MS received 3 September 2012; revised 10 August 2013; accepted 16 August 2013

\begin{abstract}
Semi-automatic control systems have the characteristics of being adaptable and requiring low energy. The objective of this research was to study the performance of an improved DSHD (Displacement Semi-Active Hydraulic Damper) by converting it to AIC (Active Interaction Control Device) with the addition of an accumulator. The prototype was tested using full-scale elements for examining the structural displacement, and typical responses of the interacting interface element developed in this research, the pressure variation of the pressure storage device, and the energy dissipation hysteresis loop when the structure installed with these elements is subjected to external force of various magnitude. The laboratory results confirm that the device developed in this research is capable of applying the energy dissipation characteristics of DSHD so that these elements are appropriate for developing the proposed AIC. The mutual interaction between the subordinate structure and the main structure to be protected is capable of transforming the quake energy applied to the main structure to the subordinate structure so that the objective of minimizing the deformation of main structural can be achieved.
\end{abstract}

Keywords. Semi-auto controller; displacement semi-active hydraulic damper; DSHD; active interaction control device; AIC.

\section{Introduction}

Strong earthquake causes tremendous deformation to civil engineering structures leading to permanent damages or collapses (Day 2007). In recent years, record-breaking earthquakes occurred globally at various locations; especially the unforgettable tsunami disaster caused by the earthquake in Indonesia, 2004 and Japan, 2011 with Richter scale of 9 prompted to think and to raise the earthquake resistance capacity of buildings.

*For correspondence 
When subject to instantaneous dynamic loadings, buildings will produce transient dynamic response so that the structural internal mechanical energy (summation of dynamic energy and potential energy) that originates from the external load, is at a higher level relatively. The rising internal energy is gradually dissipated through internal friction in the material and among elements, damping and plastic energy so that the internal energy level will eventually return to the original lowest energy point. The term 'antiseismic system' refers to the technology using various means to modify the structural dynamic characteristics with the objective of creating a safe, comfort and functional structure. The preliminary antiseismic technology started from 1945 based on the development of industrial revolution with application of hydraulic devices and electric energy devices. Then, the design concept of 'flexibility floor' was proposed to isolate the main building and its foundation to protect building. From seventies, development of new materials such as natural and synthetic rubbers has contributed to base isolation technology that have been widely applied in building and bridge in many countries. Then, Lead Rubber Bearing (LRB) was developed to apply on base isolation of building, bearing of bridge and nuclear plants. This seismic isolation technology not only to protect structures on the base isolation but also to protect main structure of building and bridge from seismic force from (1974 to 1980) such as: Rangitikei Bridge, Aurora Terrace Bridge, TocToc Bridge and King Edward Street Bridge in New Zeland and Fella 1 and Somplage in Italy. Otherwise, the term 'Structural Control' (Sannino \& Vlad 2009; Takayoshi \& Takafumi 2008; Tanaka et al 2002; Tsai et al 1999) refers to the technology using various means to modify the structural dynamic characteristics with the objective of creating a safe, comfort and functional structure. This concept was proposed from the 1980's. Generally, it consists of passive control (Ricciardelli 1999; Cimellaro et al 2009; Koh \& Martelli 2000), semi-active control (Ou \& Li 2010; Bitaraf et al 2010) and active control (Spencer et al 1998; Soong 1999; Ribakov \& Gluck 1999; Lametrie 2001; Ou \& Li 2010). Passive control systems include buckling resistant bracing (BRB), friction dampers, viscoelastic dampers, VE dampers and Passive tuned mass damper, TMD. Especially, BRB has been widely applied in Japan after Kobe earthquake of 1995. Friction dampers can be applied on old building such as ten-storey Eaton's building in Montreal, Canada and railroad and highway bridges in many countries. Viscoelastic (VE) dampers have been successfully installed in many tall buildings as a viable energy dissipating system to dissipate seismic and wind force. TMD has been applied on 87FL to 91FL of Taipei 101 to suffer seismic and wind force. SemiActive Hydraulic Damper (SHD) (Kurata et al 1999, 2000), Electrorheological Damper (Xu et al 2000), and Magnetorheological Damper (Dyke et al 1998) were widely discussed or used. Shih and Sung (2006), Shih et al (2002, 2003, 2010a, b) proposed accumulated semi-active hydraulic damper, displacement dependent semi-active hydraulic damper, DSHD, and velocity and displacement dependent hydraulic damper, VDHD to use various valves to dissipate energy induced by earthquake or wind from 2002. Energy-dissipating behaviour of these devices is achieved by controlling the oil flow in the hydraulic jack. Then, to extend the useful value of VDHD, a numerical analysis model was deduced from the SAP2000 nonlinear analysis program to simulate the energy-dissipating characteristics of VDHD (Shih et al 2010a, b). The first application of active control system was constructed in Kyobashi Seiwa Building, Tokyo, Japan in 1989 and designed by Kobori et al (1991a, b) This structural control system is widely discussed in the world. The difference between semi-active and active control system is the controlling system of active control need an external energy supply.

Since the concept of structural control was adopted by civil engineers, numerous active control theories and control hardware (elements) have been developed one after another. They have been applied to reduce damages for structures subject to wind and earthquake. Although, active control can reduce the response greatly for structures subject to various loads, its function is 
dependent on externally supplied energy so that the reliability of its element control is a serious concern. Hence, the application and extension of this method will face a serious obstacle. The semi-active control that is more reliable than the active control in addition to being adaptable and versatile.

In this research, an accumulator is added to the displacement-dependent semi-active hydraulic damper (Shih et al 2002) to form the semi-active AIC (Active Interaction Control) system (Wang 1997; Iwan \& Wang 1998; Zhang \& Iwan 2002a, b, c). It is based on the concept of interaction control by installing one or more subordinate structure on a traditional major structure. The subordinate structure has the property of a mass-stiffness damping vibrator. When subject to dynamic external action, the major structure and the subordinate structure may vibrate independently or together. Changes between independent or combined vibrations are accomplished through the switch of interface elements (IE). The ideal moment and method of switching are based on the principle of obtaining the maximum vibration reduction for the major structure. In this research, full-scale elements will be tested in laboratory by installing them on a structure that is subjected to various vibrations so that the hysteresis loop of the oil interface element of the pressure storage device subject to various external forces will be studied. And then, the seismic proof capability of this proposed device is tested and verified by comparison between the displacement and acceleration responses of test structure with and without installing this proposed device.

\section{Mechanisms and principle of interaction control}

The key to a successful interaction control method is the design of the interaction interface element; the major energy dissipation element is that it has interface elements (IE), provided with reversed internal force in subordinate structure (Spencer et al 1998) proposed the principle of interaction control concept as illustrated below.

As shown in figure 1a, assuming that the subordinate structure has a deformation to the right, and the motor is at the braking or clockwise rotating state, the subordinate structure is applying a force toward left to the major structure. If the movement of the major structure starts to change from right to left, the original force towards left will do positive work to the major structure to produce unfavorable influence on the building. Hence, the motor rotating direction is changed to counter-clockwise to disallow clockwise rotation as shown in figure $1 \mathrm{~b}$. From the status shown in figure $1 \mathrm{~b}$, the electrical motor exerts an active torque to push the subordinate structure toward left whereas the subordinate structure itself has a tendency to move toward left. Hence, under the

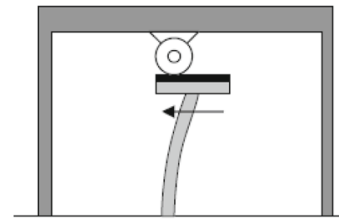

(a) Braking State

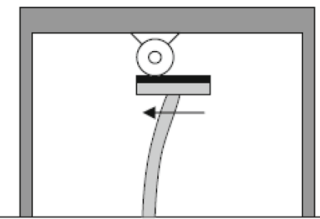

(b) Converted to counter -clockwise rotating State

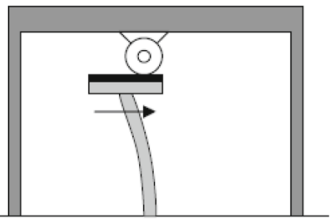

(c) Counter-clock rotation

Figure 1. The principle of interaction interface based on electrical motor counter-rotation as proposed by Iwan. 
influence of the subordinate structure potential energy and the driving force exerted by the electrical motor, the subordinate structure quickly returns to the equilibrium position, and continues to dash forward to a position that is opposite to its original position. If the friction force does not exist at this moment, the subordinate structure potential energy resumes to its original level. The driving force provided by electrical motor causes the subordinate structure to deform toward the left until it stops to reach the status as shown in figure 1c.

\section{Conformation of hydraulic interaction interface elements}

The components of this proposed hydraulic interaction interface elements are similar to that of Displacement Dependent Semi-Active Hydraulic Damper (DSHD) (Shih et al 2002). The maximum difference between this proposed device and DSHD is this proposed Hydraulic Interaction Interface Elements installed with an accumulator to improve air residue and slip defects of DSHD. So as to increase saturation pressure of oil by way of installed with an accumulator in this proposed interface elements to assist reversed internal force in subordinate structure. The conformation and oil path of Hydraulic Interaction Interface Elements is shown in figure 2.

Major components of the proposed Hydraulic Interaction Interface Elements with their functions briefly described below:

A. Hydraulic jack: The hydraulic jack is the main force transmission structure of this hydraulic interaction interface elements. It is connected by two hinges to the mass of subordinate structure and the mass of main structure. The action force of the hydraulic jack equals to the product variance between the two sides pressure of the piston and the piston area. The pressure change causes the force exertion to change.

B. Directional valve: The function of this directional valve likes the capability of railroad switch to change direction of the movement of vehicles. This function is caused by change

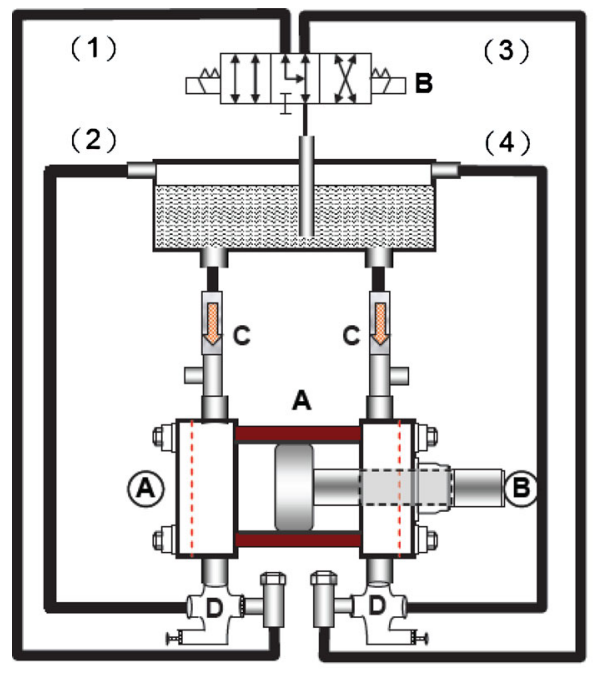

(1) Left Primary Hydraulic

Circuit

(2) Left Secondary

Hydraulic Circuit

(3) Right Primary

Hydraulic Circuit

(4) Right Secondary

Hydraulic Circuit

A Hydraulic Jack

B Directional Valve

C Check Valve

D Relief Valve

(A) Connect to Primary Struct.

(B) Connect to Auxiliary Struct.

Figure 2. The feature of hydraulic interaction interface elements. 


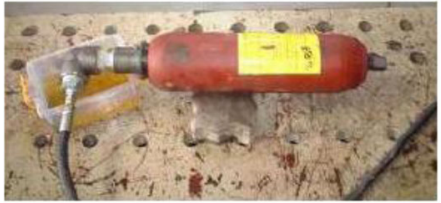

(a) Photo of Accumulator

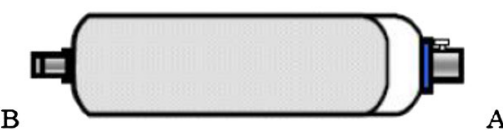

(b) symbol of Accumulator

Figure 3. Feature of accumulator of hydraulic interaction interface elements.

the flow of pressure oil path. The electromagnetism and mechanical guide pressure type are used to execute the switch flow of oil path.

C. Check valve: The check valve allows the moving oil to flow in a single direction and in this way; it can master the oil path easily. This proposed Interface Elements is formed a release of connection in one way direction by means of this valve.

D. Relief valve: The relief valve can maintain a certain value of oil pressure in the oil loop. If a set pressure is exceeded, this valve will be automatically opened to let oil to pass through resulting in pressure reduction to avoid damaging this Hydraulic Interaction Interface Elements or subordinate structure and other fixtures.

In this study, an accumulator is installed with DSHD to improve the defects of DSHD. There are two functions of accumulator: (i) maintain initial pressure; (ii) store up oil. The feature of accumulator is shown in figure 3. Figure $3 \mathrm{~b}$ shows that Point $\mathrm{A}$ is used to pressurize or leak pressure, Point B is oil gap of accumulator, connected with electromagnetic valve by oil tube.

\section{Principle of hydraulic interaction interface elements}

As shown in figure 2, if the main structure is assumed to move toward right, and the electromagnetic valve position is moved one notch toward right (figure 2), the pressure oil at the left end of the piston cannot flow out unless the current pressure is greater than the pre-selected overflow oil pressure. Currently, the hydraulic pressure cylinder can be elongated but cannot be shortened. In other words, the current interaction interface elements can only endure pressure but not tension. Hence, when the major structure moves toward right, it causes the subordinate structure to deform toward right so that the subordinate structure exerts a force to the main structure leftward.

When the structure starts to move toward left, if the electromagnetic value is pushed one notch toward left as shown in figure 2, the pressure oil at the right end of the piston cannot flow out whereas the oil at the left end can flow freely. Hence, the hydraulic pressure cylinder can shorten freely but cannot be elongated. Through such switch, the interaction interface element can only endure tension but not compression. Because the subordinate structure originally deforms toward right, once the interaction interface element loses it capability to endure compression, the interaction interface element begins to shorten causing the internal force in the subordinate structure to disappear. When the interaction interface element is subjected to a pressure that exceeds the pre-selected pressure before the element switch, the energy is stored in the energy storing device. If a sufficient quantity of high-pressure oil is stored in the pressure storing device, the oil path will even push the pressure oil from the pressure storing device into the hydraulic pressure cylinder. Hence, the subordinate structure is forced to move to the left further after it reaches the equilibrium position so that the subordinate structure is caused to exert a force leftward on the major structure. 


\subsection{Control laws of semi-active hydraulic damper}

The judging bases of semi-active control law are dependent on the relative velocity of structure and the the position where damper sets up. The optimum control order is judged by the following equation:

$$
u_{i} \bullet \dot{x}_{r, i} \leqq 0, \text { for } i=1 \text { to } N_{D} \text {, }
$$

where

$u_{i}$ is the $i$ th inner force of damper force, tension force is positive and compressive force is negative in the equation;

$\dot{x}_{r, i}$ is the relative velocity of the $i$ th damper that sets up at the story which have displaced, elongation represents positive and shortening represents negative;

$N_{D}$ is the number of dampers.

It can be known from the equation (1) that every damper is controlled independently, and the optimal situation of every damper is only related to the P-N signal of the relative velocity at the position where the damper sets up.

\subsection{Energy dissipating mathematical and test model for hydraulic-pressure interaction interface elements}

There are some assumptions for this hydraulic-pressure type interaction interface element: (i) the main structure of this test frame is a shearing building and only one horizontal degree of freedom (DOF); (ii) the degree of freedom of sub-structure is independent and one degree, which the bottom of this sub-structure is fixed at the main structure and the top of this substructure is connected with the main structure by this proposed interaction interface element; (iii) the mass of this proposed interaction interface element can be neglected by comparison with the mass of main and sub-structure; (iv) this proposed interaction interface element is rigid-plastic. This active interaction control system with the hydraulic-pressure type interaction interface element installed with the test shearing building is shown in figure 4. The surface of ground is set for a reference point for this test structure. Then, the equation of motion for the main structure with $n$ floor structure is established as equation (2) based on the relative displacement coordinates.

$$
M \ddot{x}(t)+C \dot{x}(t)+K x(t)=-M L \ddot{x}_{g}(t)+u(t)+u_{2}(t),
$$

where:

$M$ is the $n \times n$ matrix of the mass matrix of the main structure.

$C$ is the $n \times n$ matrix of the damping matrix of the main structure.

$K$ is the $n \times n$ matrix of the stiffness matrix of the main structure.

$\ddot{x}, \dot{x}, x$ are the acceleration, velocity and displacement with $n$ dimension of main structure, relative to the surface of the ground respectively.

$L$ is unit vector with $n$ dimension. $\ddot{x}_{g}$ is a scalar of ground acceleration. $u$ is the vector of control force. $u_{2}$ is the force of sub-structure, transited to supported floor.

The sub-structure can be considered as a Resonator, the equation of motion of each substructure is deduced as follows:

$$
m_{a, j} \ddot{x}_{a, j}(t)+c_{a, j} \dot{x}_{a, j}(t)+k_{a, j} x_{a, j}(t)=-m_{a, j} \ddot{x}_{g}(t)+c_{a, j} \dot{x}_{i-1}(t)+k_{a, j} x_{i-1}(t)-u_{i}(t),
$$

where:

The suffix $a, i$ represents that the systemic parameter of the sub-structure of the $i^{\text {th }}$ floor; $u_{i}(t)$ is the $i^{\text {th }}$ element force of interaction element. 


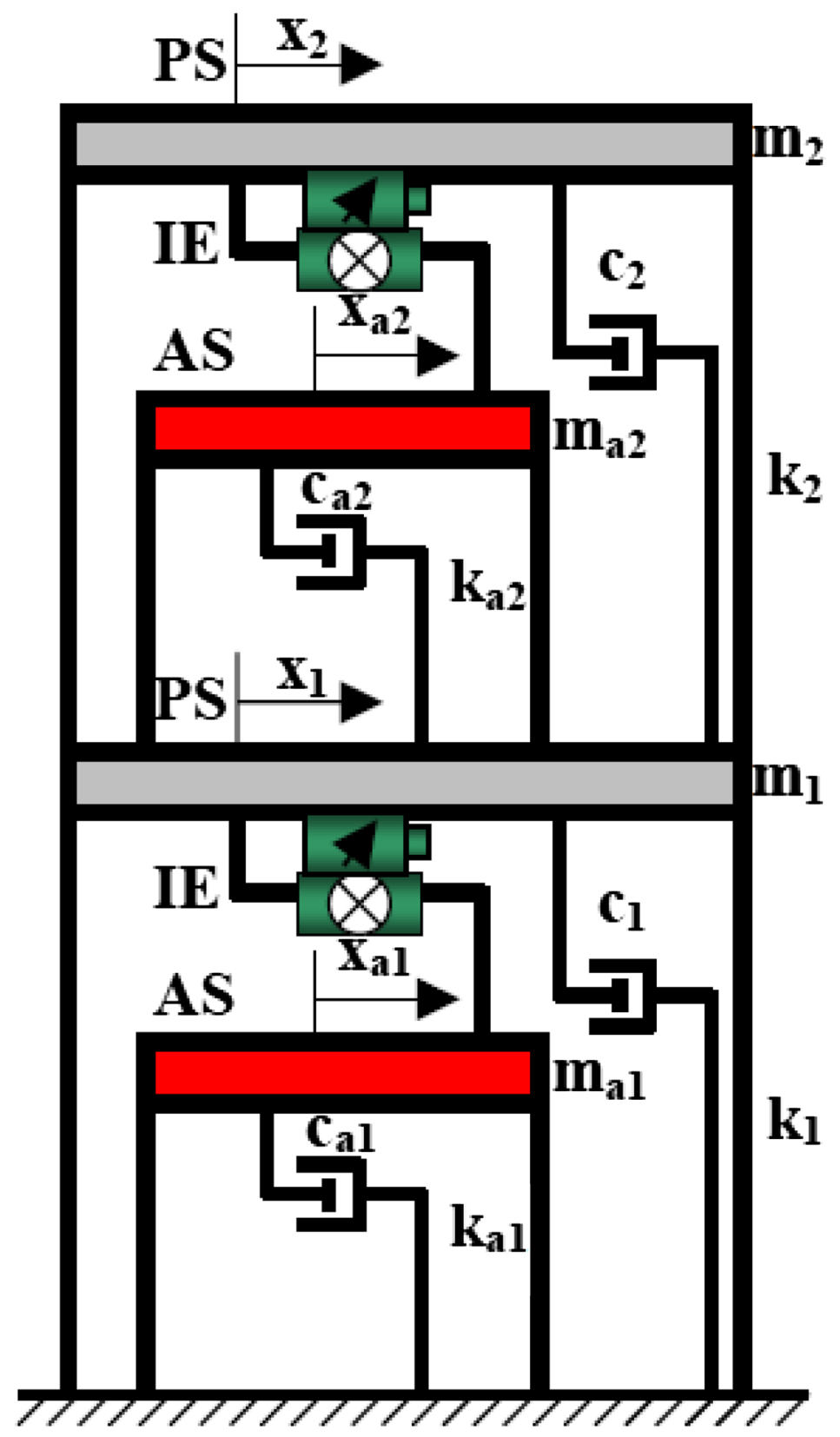

Figure 4. The Frame structure installed with this proposed active interaction control device.

Otherwise, the vector of control force is related to the internal force of the interaction interface and the status of element, it can be defined as two formulas:

(i) The element of the interaction interface is shut down (the main and sub-structure structure are joined):

$$
u_{i}(t)=-\left(m_{a, i}\left(\ddot{x}_{a, i}(t)+\ddot{x}_{g}(t)\right)+k_{a, i}\left(x_{a, i}(t)-x_{i-1}(t)\right)+c_{a, i}\left(\dot{x}_{a, i}(t)-\dot{x}_{i-1}(t)\right)\right) .
$$




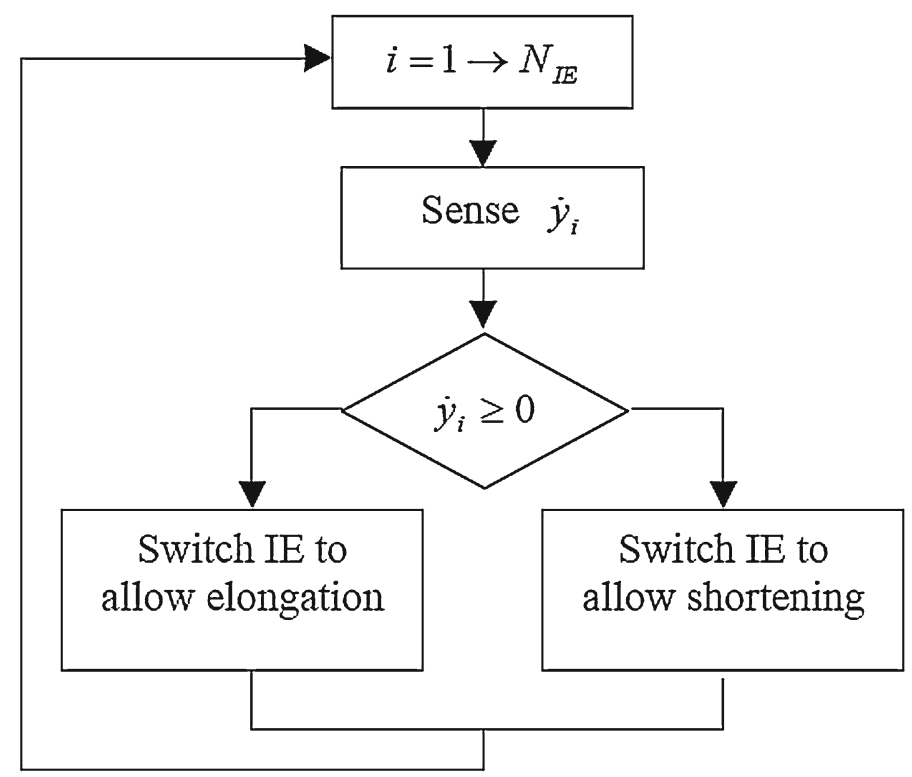

Figure 5. Control flowchart of this proposed active interaction control device.

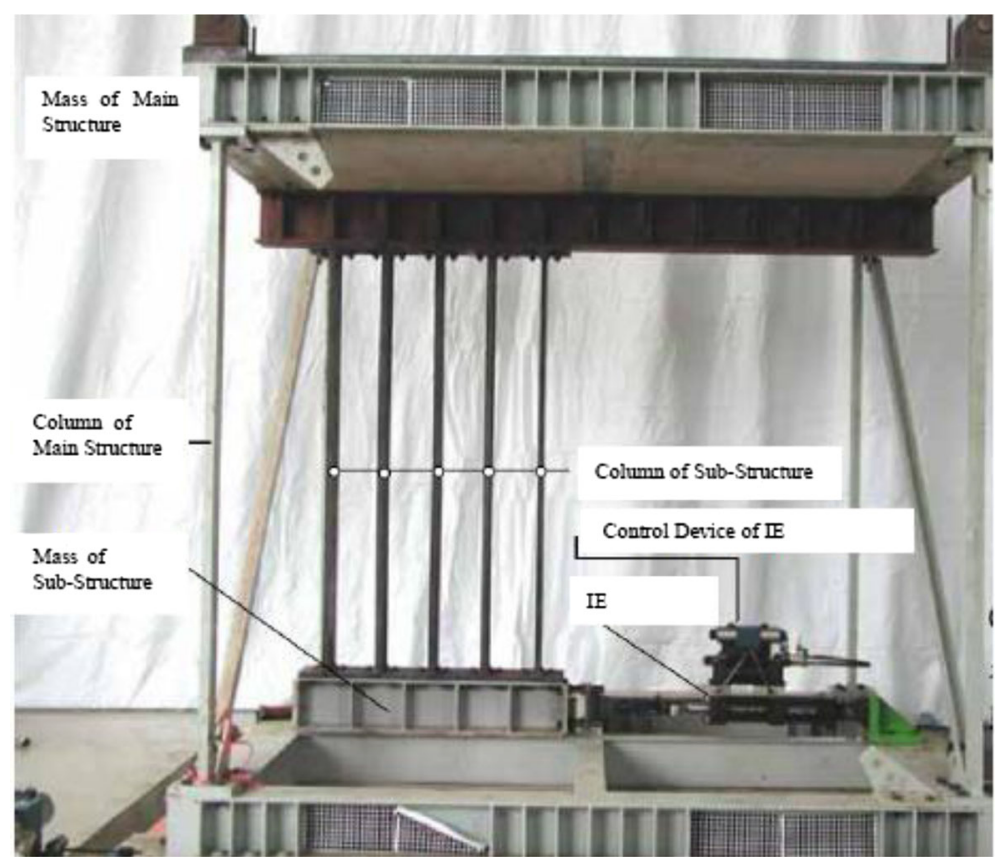

Figure 6. The test shearing building installed with this proposed device. 
If the mass of sub-structure is very light, it can be neglected. The above equation can be expressed as:

$$
\left.u_{i}(t)=k_{a, i}\left(x_{a, i}(t)-x_{i-1}(t)\right)+c_{a, i}\left(\dot{x}_{a, i}(t)-\dot{x}_{i-1}(t)\right)\right),
$$

or the velocity of sub-structure is the same as the upper floor, then, equation (4) can be expressed as follows

$$
\left.u_{i}(t)=k_{a, i}\left(x_{a, i}(t)-x_{i-1}(t)\right)+c_{a, i}\left(\dot{x}(t)-\dot{x}_{i-1}(t)\right)\right) .
$$

(ii) The element of the interaction interface is open (the main and sub-structure structure are untied):

$$
u_{i}(t)=0 .
$$

The control flowchart of this proposed active interaction control device is shown in figure 5. This proposed device is dependent on the direction of velocity to switch the interaction element (IE) to allow elongation or shortening.

In the laboratory, the hydraulic-pressure type interaction interface element as proposed in this research is installed on a structure for studying the structural displacement and acceleration response of test structure, subjected to El Centro earthquake record with peak ground acceleration $\mathrm{PGA}=345$ gal. The test shearing building is shown in figure 6 . The time history of structural

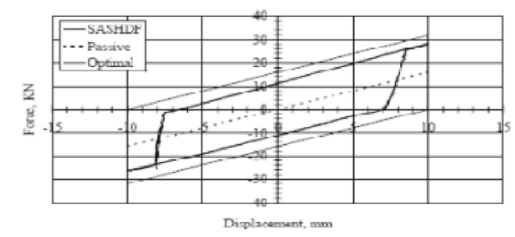

(1) $0.1 \mathrm{~Hz}$

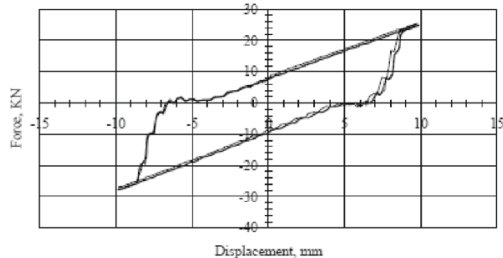

(3) $1.0 \mathrm{~Hz}$

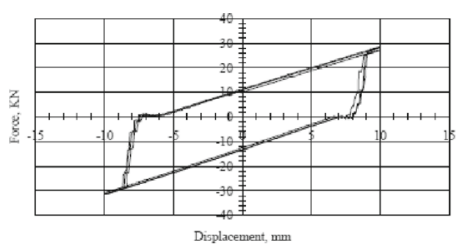

(2) $0.5 \mathrm{~Hz}$

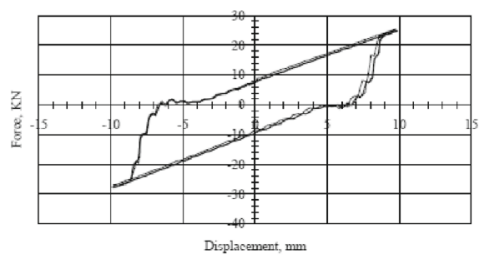

(4) $1.5 \mathrm{~Hz}$

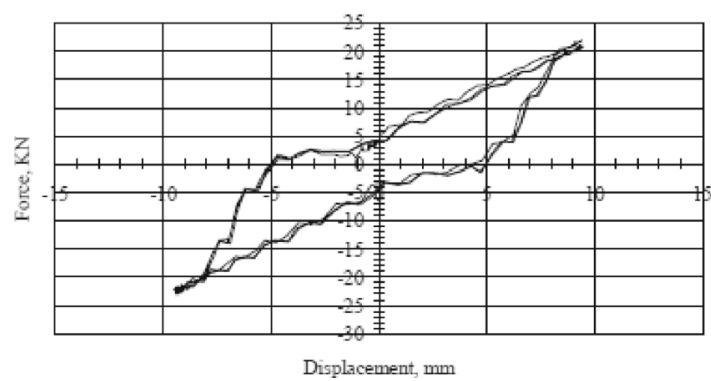

(5) $2.0 \mathrm{~Hz}$

Figure 7. The hysteretic loops of test structure subjected to $10 \mathrm{~mm}$ amplitude with various frequencies $(\mathrm{SDSHD}=36 \mathrm{kN} \mathrm{Amp}=10 \mathrm{~mm}$ ). 
displacement and acceleration responses of test structure installed with the interface element and pressure storing device, and the hysteresis loop of interface element for the hydraulic-pressure type interface element are studied.

\section{Experimental results}

The responsive behaviour of interaction interface element for the hydraulic-pressure system equipped with a pressure storing device can be grouped in four categories as shown below:

(i) Typical hysteretic loops of test structure installed with active interaction interface device are shown in figure $7(1) \sim(5)$, caused by small external vibration $(10 \mathrm{~mm})$ with various frequency that does not lead to the phenomenon of pressure storing. The internal force of this proposed device is between $-36 \mathrm{kN}$ to $+36 \mathrm{kN}$.

(ii) External vibration of amplitude scale up to $20 \mathrm{~mm}$ will cause the phenomenon of saturate about $30 \mathrm{kN}$ at Accumulator. Under periodic reciprocating variations, the internal force of subordinate structure (i.e., the internal force in the interaction interface element) is sufficient to pressurize the liquid oil into the pressure storing device. Hence, the relationship between the internal force and displacement is nonlinear. The most of external vibration will be absorbed by accumulator, then, the internal force in the interface element (IE) is only about $-20 \mathrm{kN}$ to $+20 \mathrm{kN}$. However, the pressure in the pressure storing device is

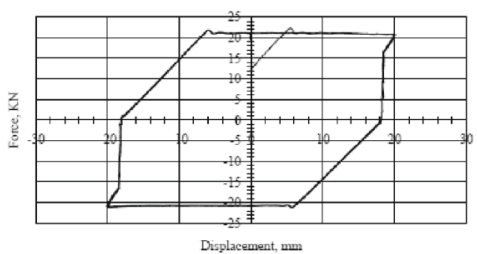

(1) $0.1 \mathrm{~Hz}$

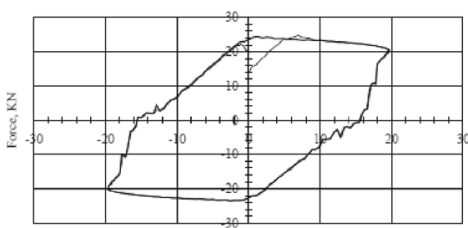

Dipplacenent, nm

(3) $1.0 \mathrm{~Hz}$

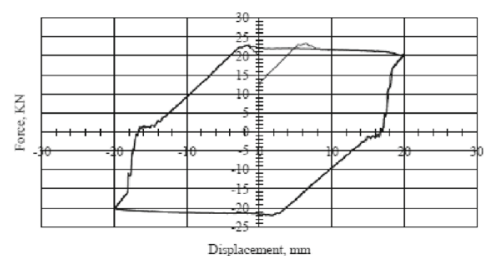

(2) $0.5 \mathrm{~Hz}$

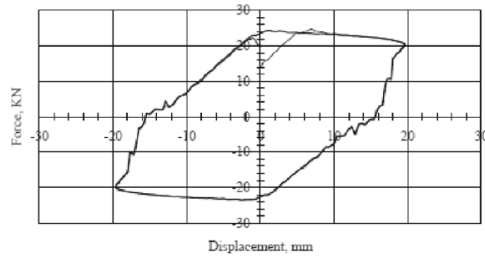

(4) $1.5 \mathrm{~Hz}$

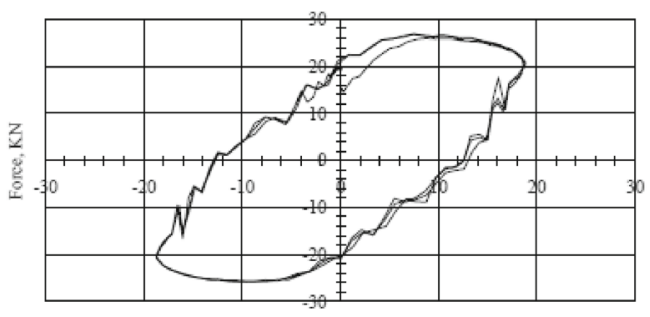

Displacement, mm

(5) $2.0 \mathrm{~Hz}$

Figure 8. The hysteretic loops of test structure subjected to $20 \mathrm{~mm}$ amplitude with various frequencies $(\mathrm{SDSHD}=20 \mathrm{kN}$ Acc. $=30 \mathrm{kN}, \mathrm{Amp}=20 \mathrm{~mm})$. 
not high enough so that when the device is disconnected, the oil flows out of the pressure storing device before the subordinate structure returns to its equilibrium position. Thus, the pressure is insufficient to push the subordinate structure to the opposite direction. The hysteretic loops of test structure installed with active interaction interface device are shown in figure $8(1) \sim(5)$.

(iii) When external amplitude vibration is up to about $25 \mathrm{~mm}$, it causes the phenomenon of pressure storing. The large reciprocating displacement leads to great structural internal force (about $40 \mathrm{kN}$ ) that is sufficient to force oil into the pressure storing device mostly. Hence, a large quantity of high-pressure oil is stored in the pressure storing device about $-40 \mathrm{kN}$ to $+40 \mathrm{kN}$. When the system is at the interface element switching status, the oil stored in the hydraulic storing device. It assists the subordinate structure in returning to its equilibrium position firstly, and then, the subordinate structure is forced to move to the opposite deformation direction until the pressure in the pressure storing device becomes too low to further push the subordinate structure. The resulting hysteric loop approaches a rectangular indicating that a perfect energy dissipation ratio is achieved. The hysteretic loops of test structure installed with active interaction interface device are shown in figure $9(1) \sim(5)$.

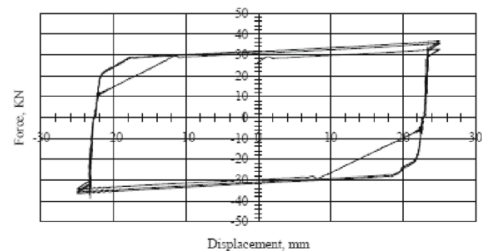

(1) $0.1 \mathrm{~Hz}$

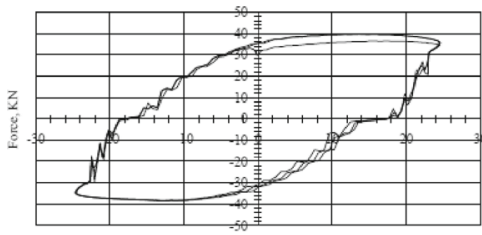

(3) $1.0 \mathrm{~Hz}$

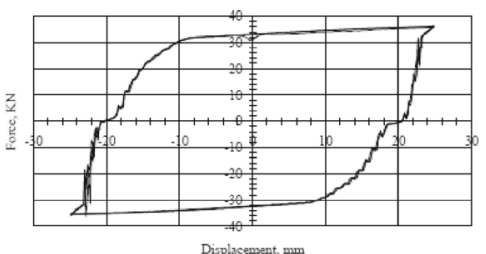

(2) $0.5 \mathrm{~Hz}$

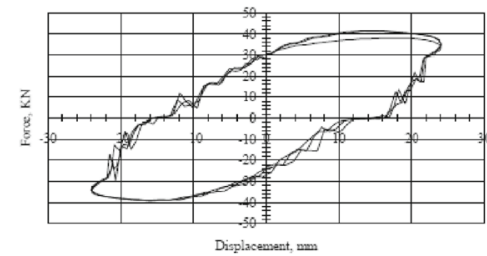

(4) $1.5 \mathrm{~Hz}$

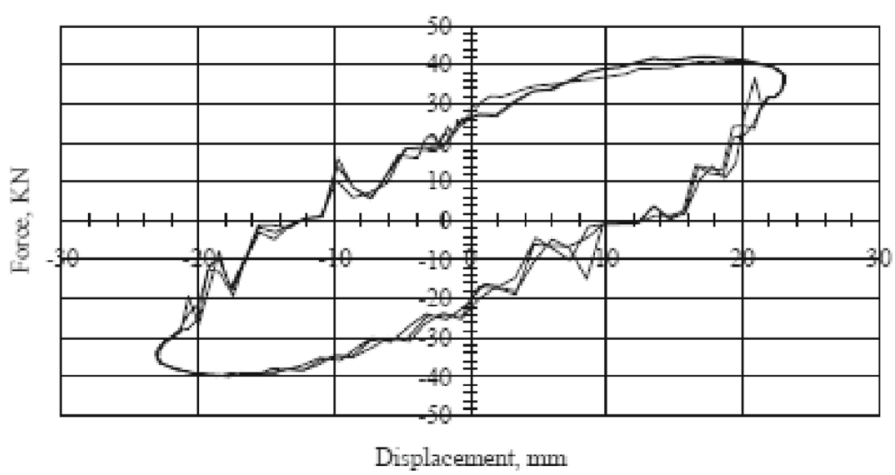

(5) $2.0 \mathrm{~Hz}$

Figure 9. The hysteretic loops of test structure subjected to $25 \mathrm{~mm}$ amplitude with various frequencies $(\mathrm{SDSHD}=40 \mathrm{kN}$ Acc $=30 \mathrm{kN}, \mathrm{Amp}=25 \mathrm{~mm})$. 


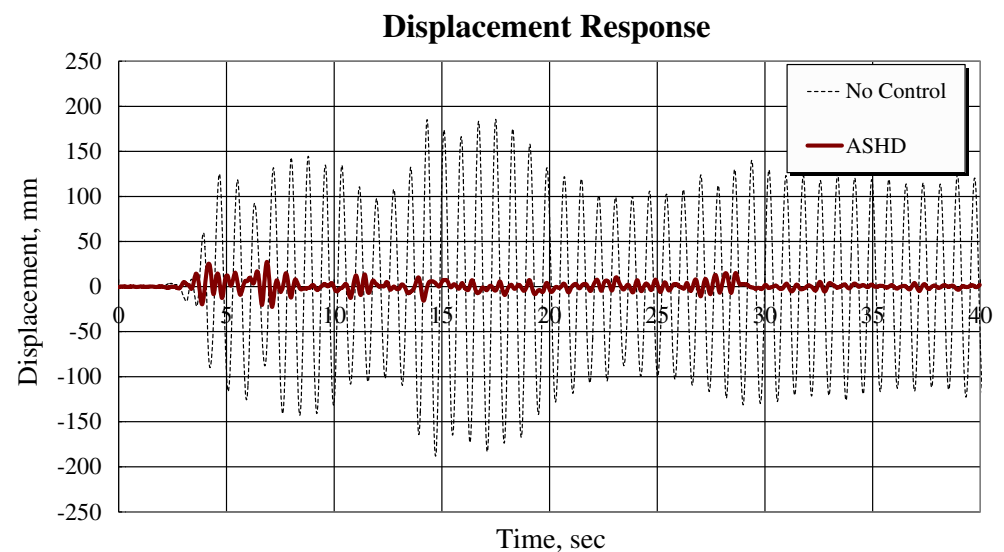

(1) The time history of displacement response of test structure

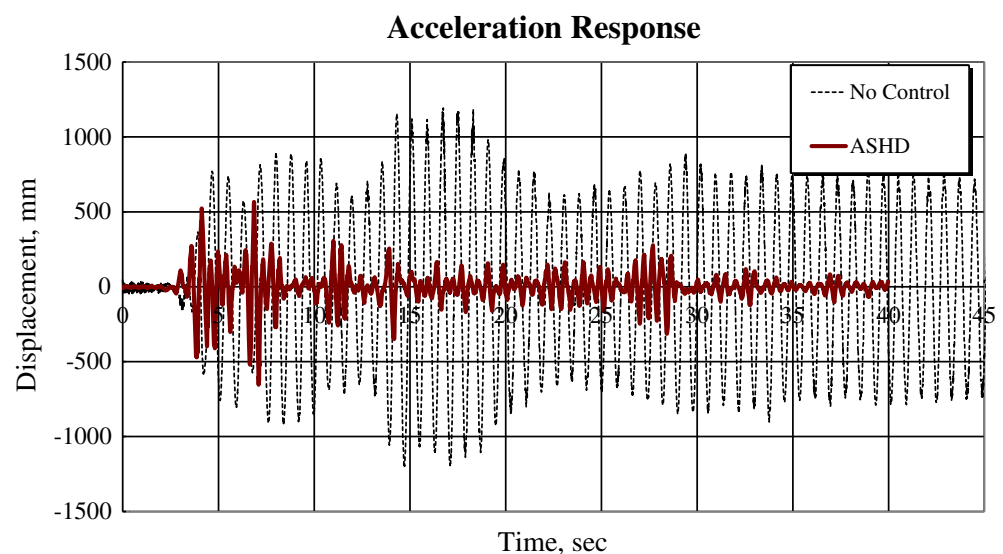

(2) The time history of acceleration response of test structure

Figure 10. The comparison of structural responses of test structure added with or without control device.

(iv) The time history of structural responses of test structure added with this proposed device are shown in figure 10 (1), (2). Figure 10 (1) and (2) are the comparison between the time history of structural displacement and acceleration responses of test building installed with and without this proposed device, respectively.

\section{Discussions}

The full scale shaking table test results of figure 10 reveal that the structural displacement and acceleration responses of test building installed with this proposed device are substantially less than those of test building without control. The energy-dissipating capability of this proposed device can be tested and verified by this test.

From these experimental results of figures 7-9, all of energy-dissipating phenomena are shown in figure 11. These phenomena can be explained as follows: 


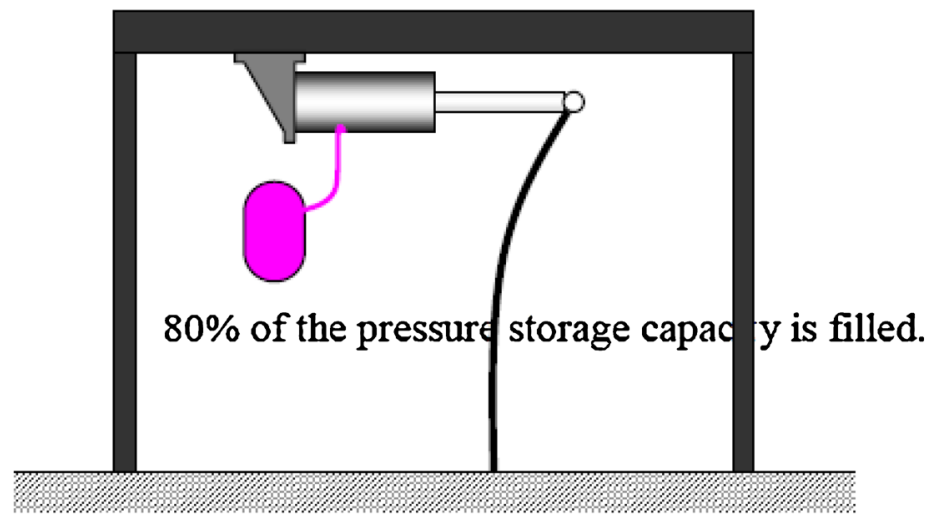

(a) The major structure moves toward right.

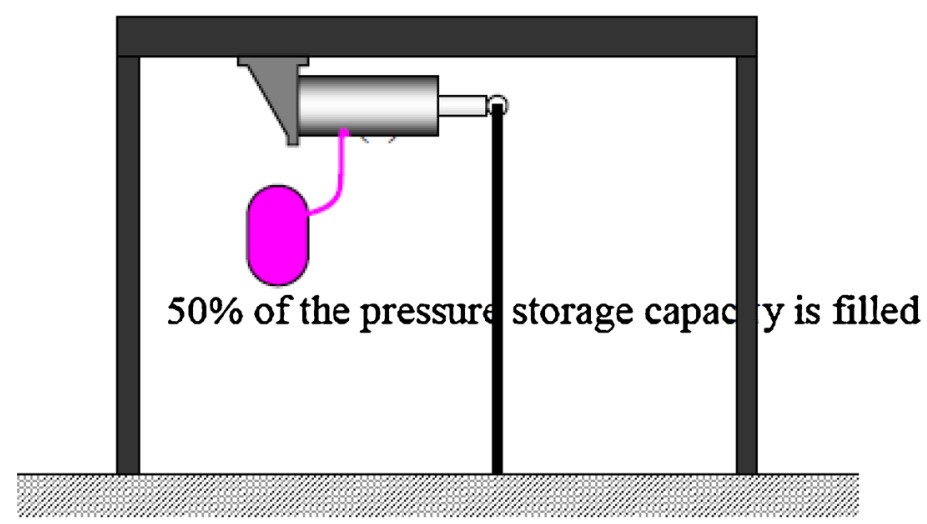

(b) The major structure starts to moves toward right.

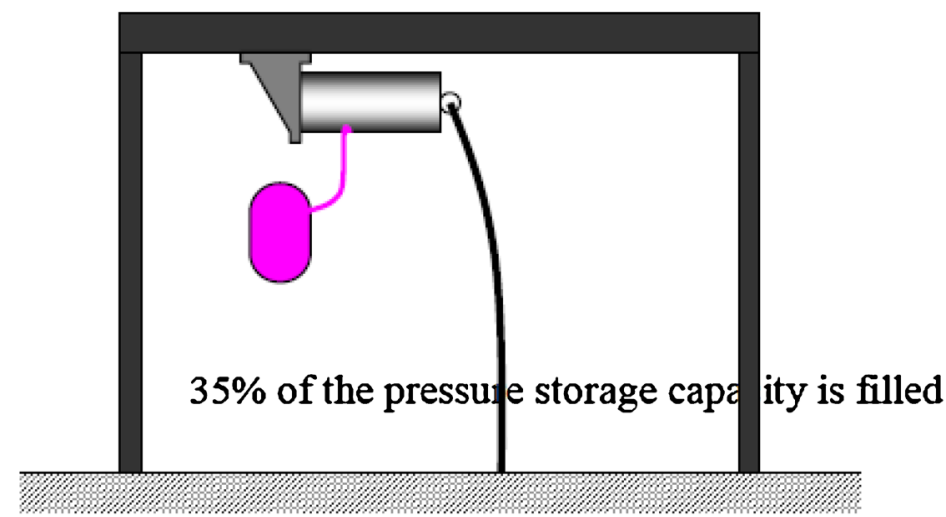

(c) The major structure continues to moves toward right.

Figure 11. Energy-dissipating behaviour for hydraulic-pressure interaction interface elements.

(i) The electromagnetic valve allows elongation only; it does not allow shortening. Currently, $80 \%$ of the pressure storage device capacity is filled, shown in figure 11a. When the major structure starts to move to the left, the position of the electromagnetic valve is switched. 
(ii) The electromagnetic valve allows shortening only; it does not allow elongation. The internal force of subordinate structure causes the oil pressure cylinder to shorten. Part of the pressure oil stored in the press storage device is forced into the oil pressure cylinder accelerator causing the latter to deform leftward until it reaches a neutral position. Currently, the pressure storage device has $50 \%$ of its capacity remaining, shown in figure $11 \mathrm{~b}$.

(iii) The electromagnetic valve allows shortening only; it does not allow elongation. The pressure oil in the oil pressure cylinder is forced into the oil pressure cylinder until the pressure in the pressure storage device equals to the pressure induced by the subordinate structure. Currently, the pressure storage device has $35 \%$ of its capacity remaining, shown in figure 11c.

(iv) From the test results of figures 7-9 show that when this proposed device under excitation at low frequency the hysteretic loops of this proposed device can perform full of energy-dissipating capability. The energy-dissipating capacity of this proposed device will be reduced as the vibration frequency increase. Nevertheless, this proposed device still can display high energy-dissipating capability.

(v) Figures 8 and 9 reveal that when the vibration amplitude increases, the phenomenon of pressure storing will be switched on to dissipate the external energy. Actually, the defects of hysteretic loops of this proposed device happened at high frequency. These defects will have increase of frequency. Although when the high frequency causes the faster releasing frequency of interaction interface, this accumulator still can storage oil to dissipate the external vibration energy.

\section{Conclusions}

The experimental results show that the interaction interface element developed in this research does not have a fixed energy dissipating behaviour when the structure is subjected to external forces of various magnitudes. However, using an accumulator that may store pressure caused by external force will cope with the reciprocal structural movement to avoid the damages caused by excessive external forces so that the structure can be fully protected.

Results obtained from the structure installed with the energy dissipating interface element in the laboratory, also show that the structural response is not large when small external force is applied so that the structural safety is not jeopardized. When this happens, the structural function or the comfort of the inhabitant is of major concern. Because pressure storing does not occur, the switching of subordinate structure is relatively mild without causing too much impact and acceleration reaction. The structural safety is threatened only when structure is subjected to vigorous disturbance. However, when structure installed with the energy dissipating device as developed in this research, the energy storing device will maintain sufficient pressure saturation to give full scope to energy dissipation. This is the major energy dissipating characteristics of the device developed in this research.

\section{Acknowledgement}

The National Science Council of Taiwan, Republic of China supported this research through grant No. NSC 100-2625-M-260-001. 


\section{References}

Bitaraf M, Ozbulut O E, Hurlebaus S and Barroso L 2010 Application of semi-active control strategies for seismic protection of buildings with MR dampers. Engineering Structures 32: 3040-3047

Cimellaro G P, Lavan O and Reinhorn A M 2009 Design of passive systems for control of inelastic structures. Earthquake Engineering \& Structural Dynamics 38(6): 783-804

Day R W 2007 Geotechnical earthquake engineering handbook. McGraw Hill Professional, USA

Dyke S J, Spencer Jr B F, Sain M K and Carlson J D 1998 An experimental study of MR dampers for seismic protection. Journal of Smart Materials and Structures: Special Issue on Large Civil Structures 7(5): 693-703

Iwan W D and Wang L I 1998 A comparison of control algorithms for active interaction control of Civil engineering. Proceedings of the second world conference on structural control. Vol. 2, Kyoto, Japan

Kobori T, Koshika N, Yamada K and Ikeda Y 1991a Seismic-response-controlled structure with active mass driver system. Part 1: design. Earthquake Engineering and Structural Dynamics 20(2): 133-149

Kobori T, Koshika N, Yamada K and Ikeda Y 1991b Seismic-response-controlled structure with active mass driver system. Part 2: verification. Earthquake Engineering and Structural Dynamics 20(2): 151-166

Koh H M and Martelli A 2000 An Overview on Recent Application of the Innovative Anti-Seismic Techniques and Needs for Further R\&D Activity. Proceedings of the Post-SMiRT Conference Seminar, Cheju, Korea, 1999, Seoul, Korea, 2000

Kurata N, Kobori T, Ishibashi T, Niwa N, Tagami J and Midorikawa H 2000 Forced vibration test of a building with semi-active damper system. Earthquake Engineering and Structural Dynamics 29: $629-645$

Kurata N, Kobori T, Takahashi M, Niwa N and Midorikawa H 1999 Actual seismic response controlled building with semi-active damper system. Earthquake Engineering and Structural Dynamics 28: $1427-1447$

Lametrie C W 2001 Parsons Brinckerhoff Automotive Division, Southeast Michigan Project Team

Ou J and Li H 2010 Design approaches for active, semi-active and passive control systems based on analysis of characteristics of active control force. Earthquake Engineering and Engineering Vibration 8(4): 493-506

Ribakov Y and Gluck J 1999 Active control of MDOF structures with supplemental electrorheological fluid dampers. Earthquake Engineering \& Structural Dynamics 28: 143-159

Ricciardelli F 1999 A linear model for structures with tuned mass dampers. Wind \& Structures 2(3): 151-171

Sannino U and Vlad I 2009 Anti-seismic systems: history, development and scientific basis. Buletinul AGRI nr. 2-3: 258-265

Shih M H and Sung W P 2006 Development and seismic reduction performance of velocity and displacement dependent hydraulic damper. Experimental Techniques 30(3): 41-45

Shih M H, Sung W P and Go C G 2002 Development of accumulated semi-active hydraulic damper. Experimental Techniques 26(5): 29-32

Shih M H, Sung W P and Go C G 2003 A design concept with a displacement dependent semi-active hydraulic damper for energy-dissipating. Experimental Techniques 27(6): 53-56

Shih M H, Sung W P and Chen C L 2010a Earthquake proof efficacy of Velocity and Displacement Dependent Hydraulic Damper (VDHD) for R.C. structures. The Structural Design of Tall and Special Buildings 19(5): 479-496

Shih M H, Sung W P and Wu M J 2010b Development of numerical modeling of analysis program for energy-dissipating behavior of velocity dependent hydraulic damper. Sadhana - Academy Proceedings in Engineering Science 35(5): 631-647

Soong T T 1999 Active Structural Control: Theory and Practice, New York: Longman

Spencer Jr B F, Sain M K and Carlson J D 1998 Smart Dampers for Seismic Protection of Structures: A Full-Scale Study. Proceedings of the 2nd World Conference on Structural Control (2WCSC)

Takayoshi K and Takafumi F 2008 State of the art of development and application of antiseismic systems in Japan. AIP Conference Proceedings 1020: 1255-1271 
Tanaka T, Yamamoto M, Katayama T, Nakahira K, Yamane K, Shimano Y and Hirayama K 2002 Recent applications of structural control to high rise building. Earthquake Engineering and Engineering Seismology 4(1): 75-93

Tsai C-S et al 1999 Nonlinear behaviour of structures with added passive devices. Proceedings of the Second World Conference on Structural Control 1: 309-318

Wang L J 1997 Active interaction control for civil structures. Technical Report: CaltechEERL:EERL-97-04. California Institute of Technology

Xu Y X, Qu W L and Ko J M 2000 Seismic response control of frame structures using magnetorheological/electrorheological dampers. Earthquake Engineering and Structural Dynamics 29: 557-575

Zhang Y and Iwan W D 2002a Active interaction control of tall buildings subjected to near-field ground motions. Journal of Structural Engineering, ASCE 128(1): 69-79

Zhang Y and Iwan W D 2002b Active interaction control of civil structures. Part 1: SDOF systems. Earthquake Engineering \& Structural Dynamics 31: 161-178

Zhang Y and Iwan W D 2002c Active interaction control of civil structures. Part 2: MDOF systems. Earthquake Engineering \& Structural Dynamics 31: 179-194 